\title{
ANALISIS KINERJA DI SIMPANG EMPAT TAK SEBIDANG KOTA MAKASSAR BERBASIS MIKROSIMULASI
}

\author{
Muhammad Rusmin \\ Teknik Sipil \\ Universitas Hasanuddin \\ Kampus II FT-UH Jl. Poros Malino Km. 6, \\ Borongloe, Bontomaranu, Kabupaten Gowa \\ rusminrahman@yahoo.com
}

\author{
M. Isran Ramli \\ Teknik Sipil \\ Universitas Hasanuddin \\ Kampus II FT-UH J1. Poros Malino Km. 6, \\ Borongloe, Bontomaranu, Kabupaten Gowa \\ misranramli@yahoo.com
}

\begin{abstract}
Traffic volume surveys are one of the simplest methods to get traffic data to better understand optimization and efficiency so as to minimize traffic congestion problems on the road. The method used is based on descriptive and analytical methods, which is done classify vehicles in the class manually by counting the number of vehicles per unit time based on the class. The purpose of the traffic survey volume conducted at Simpang four Jalan Penghibur - Jalan Metro Tanjung Bunga, Regency / City Makassar during the period of April 2017, the result that can be found is the level of saturation of the highway that is still in an acceptable level. Traffic flow analysis at the study sites is still below the congestion limit. It is advisable to add another road option to the Metro flower promenade that is not too far away or make a light trafick on the intersection of the four.
\end{abstract}

Keywords: traffic volume survey, intersection of four J1. Penghibur, street saturation level

\begin{abstract}
Abstrak
Survei volume lalu lintas merupakan salah satu metode yang paling sederhana untuk mendapatkan data lalu lintas agar lebih memahami optimalisasi dan efisiensi sehingga dapat meminimalisasi masalah kemacetan lalu lintas kendaraan di jalan raya. Metode yang digunakan didasarkan pada metode deskriptif dan analitis, yang dilakukan adalah mengklasifikasikan kendaraan di kelas secara manual dengan menghitung jumlah kendaraan per satuan waktu berdasarkan kelas. Tujuan dari volume survei lalu lintas yang dilakukan di Simpang empat Jalan Penghibur - Jalan Metro Tanjung Bunga , Kabupaten/Kota Makassar selama periode April 2017, hasil yang dapat ditemukan adalah tingkat kejenuhan jalan raya yang masih dalam tingkat yang dapat diterima. Analisis arus lalu lintas di lokasi penelitian masih di bawah batas kemacetan. Disarankan agar menambahkan opsi jalan lain menuju jalan Metro tanjung bunga yang tidak terlalu jauh atau membuat trafic light dijalan simpang empat tersebut.
\end{abstract}

Kata Kunci: survei volume lalu lintas, simpang empat Jl. Penghibur, tingkat kejenuhan jalan

\section{PENDAHULUAN}

\section{Latar Belakang}

Kendaraan yang beroperasi di jalan memiliki perbedaan dimensi, berat, radius putar, tenaga penggerak, jenis mesin dan sebagainya. Survei volume lalu lintas terklasifikasi yang dilakukan adalah salah satu metoda paling sederhana untuk mendapatkan data lalu lintas serta menyediakan berbagai informasi yang bermanfaat untuk optimalisasi dan data perhitungan volume lalu lintas adalah informasi dasar untuk perencanan, desain, manajemen hingga pengoperasian jalan sehingga lebih memahami optimalisasi dan efisiensi lalulintas kendaraan dan meminimalkan masalah kemacetan di jalan raya. efisiensi lalulintas kendaraan dan meminimalkan masalah kemacetan di jalan raya. Untuk 
kemudahan dalam analisis maka kendaraan dikelompokkan (diklasifikasikan) ke dalam kelas-kelas. Survei volume lalu lintas secara manual dapat dengan mudah dilakukan dengan menghitung jumlah kendaraan per satuan waktu berdasarkan kelas-kelasnya. Tujuan survei volume lalu lintas terklasifikasi ruas jalan adalah untuk (1) Menjelaskan pengertian volume lalu lintas terklasifikasi, (2), Melakukan survei volume lalu lintas terklasifikasi secara manual dan (3) Menyajikan data volume lalu lintas terklasifikasi. Metode yang dilakukan adalah dengan mengelompokan kendaraan dalam kelas kelas secara manual dengan menghitung jumlah kendaraan persatuan waktu berdasarkan kelas kelasnya. Hasil dari pembahasan tersebut dapat digunakan untuk kebutuhan:

- Desain geometrik jalan (kecepatan desain, kelandaian, radius);

- Desain struktur konstruksi perkerasan jalan dan jembatan;

- Manajemen lingkungan (kebisingan, atap, getaran), manajemen angkutan barang dan manajemen angkutan umum;

- Perhitungan ekonomi termasuk biaya operasi kendaraan, nilai waktu orang (personal time), biaya kelambatan dan lain-lain.

\section{Pembatasan Masalah}

- Lokasi penelitian di fokuskan pada simpang empat tak bersinyal empat lengan di Jl.Penghibur - Jl. Metro Tanjung Bunga

- Kinerja simpang tak bersinyal dianalisa berdasarkan MKJI 1997

\section{LANDASAN TEORI}

\section{Simpang}

Persimpangan merupakan titik pada jaringan jalan dimana jalan-jalan bertemu dan dimana lintasan lintasan kendaraan yang saling berpotongan. Persimpangan merupakan factor yang paling penting dalam menentukan kapasitas dan waktu perjalanan pada suatu jaringan jalan, khususnya daerah perkotaan. (Studi Transportation Engineering I DLLAJR, 1987,

\section{Simpang Tak Bersinyal}

\section{Prinsip Umum}

Ukuran-ukuran kinerja dapat diperkirakan untuk kondisi tertentu sehubungan dengan geometri, lingkungan dan lalu-lintas dengan metode :

- Kapasitas

- Tundaan

- Derajat Kejenuhan

- Peluang Antrian

Ukuran-ukuran Kinerja Simpang Tak Bersinyal

- Kapasitas

- Tundaan

- Derajat Kejenuhan

- Peluang Antrian

c. Prosedur Analisa Kinerja Simpang Tak Bersinyal Metode MKJI 1997 Data Masukan

1. Data Geometri

- a.Sketsa pola geometri yang terdiri dari nama jalan minor, nama jalan utama, nama kota, dan nama pilihan dari alternative rencana.

- b.Sketsa simpang yang memberikan gambaran yang baik dari suatu simpang mengenai informasi kereb, lebar, jalur, bahu dan median. 
- c.Sketsa simpang yang membuat nama jalan minor, nama jalan utama, dan gambar suatu panah yang menunjukan arah.

2. Kondisi Lalu-lintas

- Perhitungan arus lalu lintas dalam satuan mobil penumpang (SMP).

- Nilai normal variable umum lalu lintas.

3.Kondisi Lingkungan

- Kelas Ukuran Kota

- Tipe Lingkungan Jalan

- Kelas Hambatan Samping

- Hambatan samping ditentukan secara kualitatif dengan pertimbangan teknik lalulintas Tinggi,Sedang atau Rendah.

\section{METODOLOGI PENELITIAN}

\section{Metode dan Prosedur Survei Ruas Jalan}

Tahapan untuk pelaksanaan praktikum survei volume lalu lintas terklasifikasi ruas jalan adalah sebagai berikut:

- Melakukan pembagian jenis kendaraan dalam lalu lintas disesuaikan dengan tujuan survei.

- Kendaraan tak bermotor (UM), meliputi : sepeda, becak, gerobak, andong.

- Sepeda motor (MC), meliputi : sepeda motor roda dua dan roda tiga.

- Kendaraan ringan (LV), meliputi : mobil penumpang (minibus/station wagon, sedan, jeep), pick - up, taksi, AU (microbus), bus sedang, truk kecil, dll.

- Kendaraan berat (HV), meliputi : bus besar, truk dua as, truk tiga as, gandeng, trailer.

- Surveyor menempati suatu titik yang tetap ditepi jalan, sedemikian sehingga mendapatkan pandangan yang jelas.

Jumlah surveyor yang dibutuhkan tergantung pada:

- Volume Lalu Lintas

- Jenis Kendaraan yang dicacah.

- Petugas mencatat setiap kendaraan yang melintasi titik yang telah ditentukan setiap interval waktu yang telah ditetapkan pada formulir survei.

- Pencacahan secara manual dapat dilakukan tanpa alat yaitu dengan mencoretkan garis pada formulir survei (turus)

- Pencacahan dengan alat (counter/hand tally ) dilakukan secara komulatif dan memindahkan nilai komulatif ke dalam formulir survei setiap akhir periode.

- Melakukan pencatatan data secara terpisah untuk setiap arah arus lalu lintas dan setiap lajur.

- Menggunakan interval /periode setiap 15 menitan untuk survei sekitar 1 - 2 jam.

Peralatan yang diperlukan

- Tally counter (alat pencacah),

- Jam tangan untuk penunjuk waktu periode survei dan interval,

- Formulir isian survei,

- Alas dan peralatan tulis menulis,

- Identitas dan surat ijin survei. 
Untuk dapat mengolah data hasil survei agar dapat dihitung untuk mencari jam puncak dan arus puncaknya, semua data (nilai arus lalu lintas) di ubah menjadi satuan mobil penumpang (smp). Nilai ini menggunakan ekivalensi mobil penumpang ( emp) yang diturunkan secara empiris untuk tipe kendaraan berikut :

- Kendaraan ringan (LV) ( termasuk : sedan/carry/van, pick-up, mikrolet/bus kota, dan truk kecil )

- Kendaraan berat (HV) ( bus besar, truck 2 as, truck 3 as, truk gandeng/ trailer )

- Motorcycles (MC) (termasuk: motor roda 2 dan motor roda 3)

- Unmotorized (UM) (termasuk sepeda, becak, andong/gerobak)

Ekivalensi mobil Penumpang (emp) untuk masing-masing tipe kendaraan tergantung pada tipe jalan dan arus lalu lintas total yang dinyatakan dalam kendaraan/jam. Untuk kendaraan ringan dalam arus lalulintas emp=1.0 (MKJI, 1997).

\section{Metode dan Prosedur Kinerja Ruas jalan}

Menurut MKJI,1997,dalam perhitungan kinerja ruas jalan ada beberapa variabel yang dipakai, di antaranya:

\section{Arus dan Komposisi Lalu Lintas}

Nilai arus lalu-lintas (Q) mencerminkan komposisi lalu-lintas, dengan menyatakan arus dalam satuan mobil penumpang (smp). Semua nilai arus lalu-lintas (per arah dan total) diubah menjadi satuan mobil penumpang (smp) dengan menggunakan ekivalensi mobil penumpang (emp) yang diturunkan secara empiris untuk tipe kendaraan berikut:

- Kendaraan ringan (LV) termasuk sedan/carry/van, pick-up, mikrolet, bus

- kota, dan truk kecil.

- Kendaraan berat (HV) termasuk bus besar, truck 2 as, truck 3 as, gandeng/ trailer

- Motorcycles (MC) termasuk motor roda 2 dan motor roda 3

- Unmotorized (UM) termasuk sepeda, becak, andong/gerobak

Pengaruh kendaraan tak bermotor dimasukkan sebagai kejadian terpisah dalam faktor penyesuaian hambatan samping.

\section{Kecepatan Arus Bebas}

sebagai kecepatan pada tingkat arus nol, yaitu kecepatan yang akan dipilih pengemudi jika mengendarai kendaraan bermotor tanpa dipengaruhi oleh kendaraan bermotor lain di jalan. Kecepatan arus bebas telah diamati melalui pengumpulan data lapangan, dimana hubungan antara kecepatan arus bebas dengan kondisi geometrik dan lingkungan telah ditentukan dengan metode regresi. Kecepatan arus bebas kendaraan ringan telah dipilih sebagai kriteria dasar untuk kinerja segmen jalan pada arus $=0$. Kecepatan arus bebas untuk kendaraan berat dan sepeda motor juga diberikan sebagai referensi. Kecepatan arus bebas untuk mobil penumpang biasanya 10-15\% lebih tinggi dari tipe kendaraan ringan lain. Kecepatan arus bebas dasar (FV0) untuk tipe jalan dua lajur tak terbagi (2/2 UD) adalah 44. Faktor penyesuaian untuk lebar jalur FVw adalah -3. Faktor penyesuaian kecepatan arus bebas untuk hambatan samping (FFVSF) adalah 0.98. Faktor penyesuaian kecepatan unutk ukuran kota adalah 1 (MKJI 1997). Persamaan untuk penentuan kecepatan arus bebas sebagai berikut: 
$\mathrm{FV}=\left(\mathrm{FV}_{0}+\mathrm{FV}_{\mathrm{W}}\right) \times \mathrm{FFV}_{\mathrm{SF}} \times \mathrm{FFV}_{\mathrm{CS}}$

dimana,

$\mathrm{FV}=$ Kecepatan arus bebas kendaraan ringan pada kondisi lapangan $(\mathrm{km} / \mathrm{jam})$

$\mathrm{FV}_{0} \quad=$ Kecepatan arus bebas dasar kendaraan ringan pada jalan yang diamati

$\mathrm{FV}_{\mathrm{W}} \quad=$ Penyesuaian kecepatan untuk lebar jalan $(\mathrm{km} / \mathrm{jam})$

$\mathrm{FFV}_{\mathrm{SF}}=$ Faktor penyesuaian untuk hambatan samping dan lebar bahu atau kereb penghalang

$\mathrm{FFV}_{\mathrm{CS}}=$ Faktor penyesuaian kecepatan untuk ukuran kota

\section{Kapasitas}

sebagai arus maksimum melalui suatu titik di jalan yang dapat dipertahankan per satuan jam pada kondisi tertentu. Untuk jalan dua-lajur dua-arah, kapasitas ditentukan untuk arus dua arah (kombinasi dua arah). Nilai kapasitas dasar di jalan Raya Narogong Cileungsi (dua lajur tak berbagi, total dua arah) adalah $2900 \mathrm{smp} / \mathrm{jam}$. Oleh karena lokasi yang mempunyai arus mendekati kapasitas segmen jalan sedikit (sebagaimana terlihat dari kapasitas simpang sepanjang jalan), kapasitas juga telah diperkirakan dari analisa kondisi iringan lalulintas, dan secara teoritis dengan mengasumsikan huhungan matematik antara kerapatan, kecepatan dan arus. Kapasitas dinyatakan dalam satuan mobil penumpang (smp). Persamaan dasar untuk menentukan kapasitas adalah sebagai berikut :

$\mathrm{C}=\mathrm{C}_{0} \times \mathrm{F}_{\mathrm{CW}} \times \mathrm{FC}_{\mathrm{SP}} \times \mathrm{FC}_{\mathrm{SF}} \times \mathrm{FC}_{\mathrm{CS}}$

dimana,

$\mathrm{C} \quad=$ Kapasitas ( $\mathrm{smp} / \mathrm{jam})$

$\mathrm{C}_{0} \quad=$ Kapasitas dasar

$\mathrm{FC}_{\mathrm{W}}=$ Faktor penyesuaian lebar jalan

$\mathrm{FC}_{\mathrm{SP}}=$ Faktor penyesuaian pemisahan arah (hanya untuk jalan tak terbagi)

$\mathrm{FC}_{\mathrm{SF}}=$ Faktor penyesuaian hambatan samping dan bahu jalan/kereb.

$\mathrm{FC}_{\mathrm{CS}}=$ Faktor penyesuaian ukuran kota

\section{- Derajat Kejenuham (DS)}

sebagai rasio terhadap kapasitas, digunakan sebagai faktor utama dalam penentuan tingkat kinerja simpang dan segmen jalan. Nilai DS menunjukkan apakah segmen jalan tersebut mempunyai masalah kapasitas atau tidak. Derajat Kejenuhan dihitung dengan menggunakan arus dan kapasitas dinyatakan dalam smp/jam. DS digunakan untuk analisa perilaku lalu lintas berupa kecepatan. Persamaan untuk menghitung derajat kejenuhan adalah sebagai berikut:

$\mathrm{DS}=\mathrm{Q} / \mathrm{C}$

dimana,

$\mathrm{Q}=$ Arus dan komposisi lalu lintas

$\mathrm{C}=$ Kapasitas

\section{- Kecepatan}


Manual menggunakan kecepatan tempuh sebagai ukuran utama kinerja segmen jalan, karena mudah dimengerti dan diukur, dan merupakan masukan yang penting untuk biaya pemakai jalan dalam analisa ekonomi. Kecepatan tempuh didefinisikan dalam manual ini sebagai kecepatan rata-rata ruang dari kendaraan ringan (LV) sepanjang segmen jalan.

$\mathrm{V}=\mathrm{L} / \mathrm{TT}$

dimana,

$\mathrm{V}=$ Kecepatan rata-rata ruang $\mathrm{LV}(\mathrm{km} / \mathrm{jam})$

$\mathrm{L} \quad=$ Panjang segmen $(\mathrm{km})$

TT $=$ Waktu tempuh rata-rata LV sepanjang segmen (jam)

\section{ANALISA DAN PEMBAHASAN}

- Pengambilan Data Geometri

Tabel 1. Kondisi Geometrik masing-masing Pendekat

\begin{tabular}{cccc}
\hline No & Pendekat (Arah) & Ruas lebar efektif $(\mathrm{m})$ & Kondisi jalan \\
\hline 1 & Jl. Penghibur & 14.55 & Utama \\
\hline 2 & Jl. H. Bau & 11,92 & Minor \\
\hline 3 & Jl. Rajawali & 14,12 & Utama \\
\hline 4 & Jl.Metro Tj. Bunga & 15,79 & Minor \\
\hline
\end{tabular}

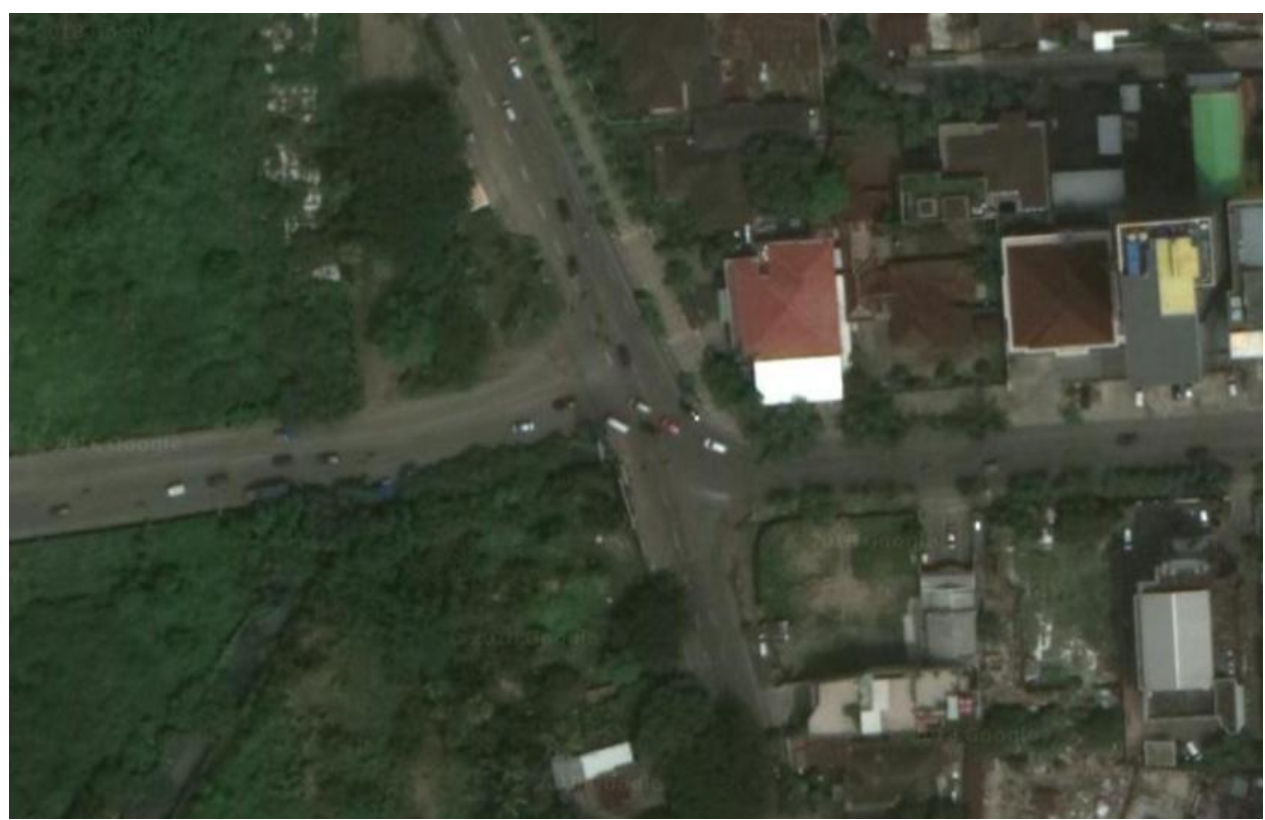

Gambar 1. Denah Lokasi 
- Data Volume Lalu Lintas

Berdasarkan hasil perhitungan Volume lalu lintas dalam dua hari tersebut diperoleh jam puncak yaitu pada jam 12.00 - 13.00 sebesar 3939,30 smp/jam.

pegamatan dapat dilihat dalam Tabel berikut ini :

Tabel 2. Rekapitulasi Volume Lalu Lintas

\begin{tabular}{|c|c|c|c|c|c|c|c|c|c|c|c|}
\hline \multirow{2}{*}{ No } & & \multicolumn{10}{|c|}{ VOLUME LALU LINTAS (Smp/Jam) } \\
\hline & WAKTU & S-LT & S-ST & S-RT & T-LT & T-ST & T-RT & B-LT & B-ST & B-RT & JUMLAH \\
\hline 1 & $06.00-07.00$ & 0 & 602,5 & 226 & 769,7 & 0 & 0 & 53,5 & 233,3 & 0 & $1.885,00$ \\
\hline 2 & $07.00-08.00$ & 0 & 830 & 345,6 & $1.002,90$ & 0 & 0 & 102,3 & 450,9 & 0 & $2.731,70$ \\
\hline 3 & $08.00-09.00$ & 0 & 987,7 & 506,4 & $1.023,10$ & 0 & 0 & 121 & 493,5 & 0 & $3.131,70$ \\
\hline 4 & $09.00-10.00$ & 0 & 991 & 576,1 & 990,7 & 0 & 0 & 105 & 486,8 & 0 & $3.149,60$ \\
\hline 5 & $10.00-11.00$ & 66 & 893,5 & 462,5 & $1.059,10$ & 0 & 0 & 95,5 & 708 & 0 & $3.284,60$ \\
\hline 6 & $11.00-12.00$ & 345,5 & 1.073 & 341 & $1.132,50$ & 0 & 0 & 123 & 663,5 & 0 & $3.678,80$ \\
\hline 7 & $12.00-13.00$ & 459,1 & 1.096 & 422,1 & $1.116,80$ & 0 & 0 & 148,1 & 697,3 & 0 & $3.939,30$ \\
\hline 8 & $13.00-14.00$ & 482,1 & 1.234 & 397,8 & $1.104,50$ & 0 & 0 & 171,7 & 491,4 & 0 & $3.881,70$ \\
\hline 9 & $14.00-15.00$ & 397,5 & 1.108 & 279,7 & 958,5 & 0 & 0 & 163,1 & 374,5 & 0 & $3.281,70$ \\
\hline 10 & $15.00-16.00$ & 448,6 & 994,9 & 313,7 & $1.023,70$ & 0 & 0 & 193,2 & 401,8 & 0 & $3.375,90$ \\
\hline 11 & $16.00-17.00$ & 482,6 & 976,9 & 251 & $1.135,30$ & 0 & 0 & 154,3 & 413,1 & 0 & $3.413,20$ \\
\hline 12 & $17.00-18.00$ & 559,4 & 1.140 & 194,5 & $1.150,50$ & 0 & 0 & 148,5 & 319,8 & 0 & $3.513,10$ \\
\hline \multicolumn{2}{|c|}{ Maksimum } & & & & & & & & & & 3939,3 \\
\hline
\end{tabular}

Grafik 1. Volume Lalu Lintas

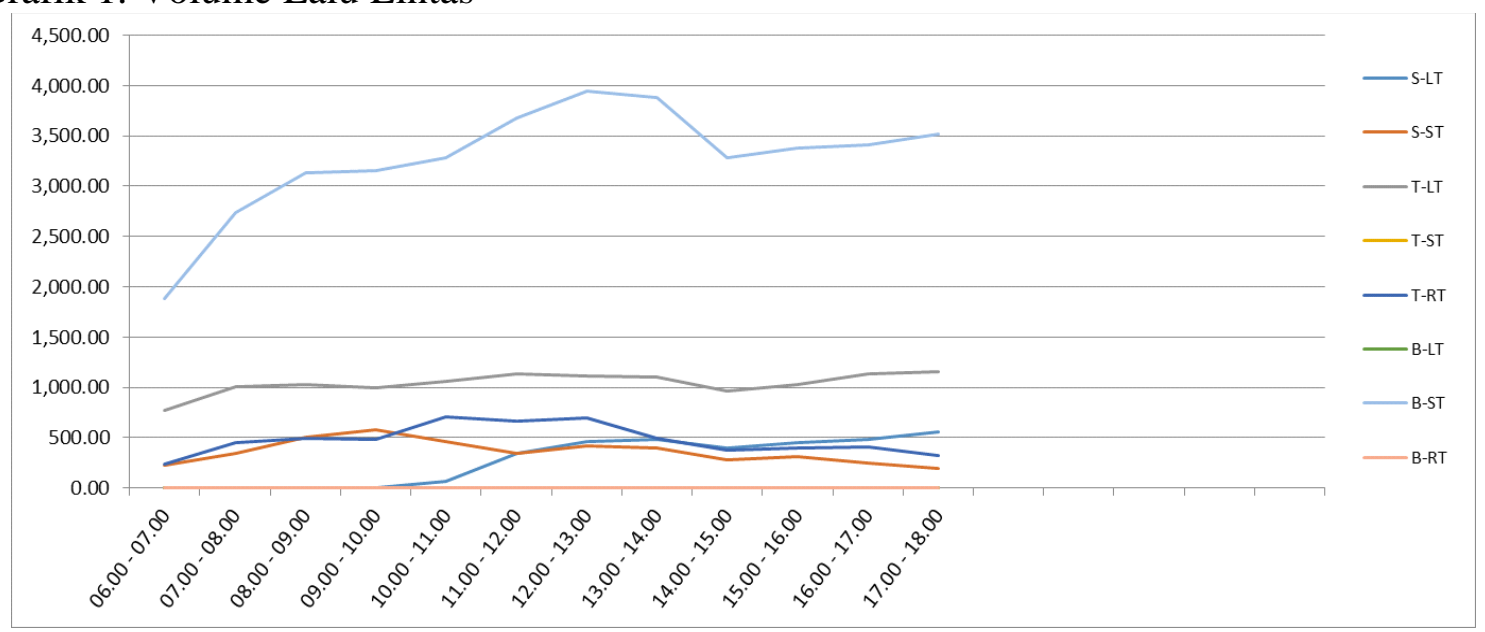

Grafik 2. Jumlah Volume Lalu Lintas 


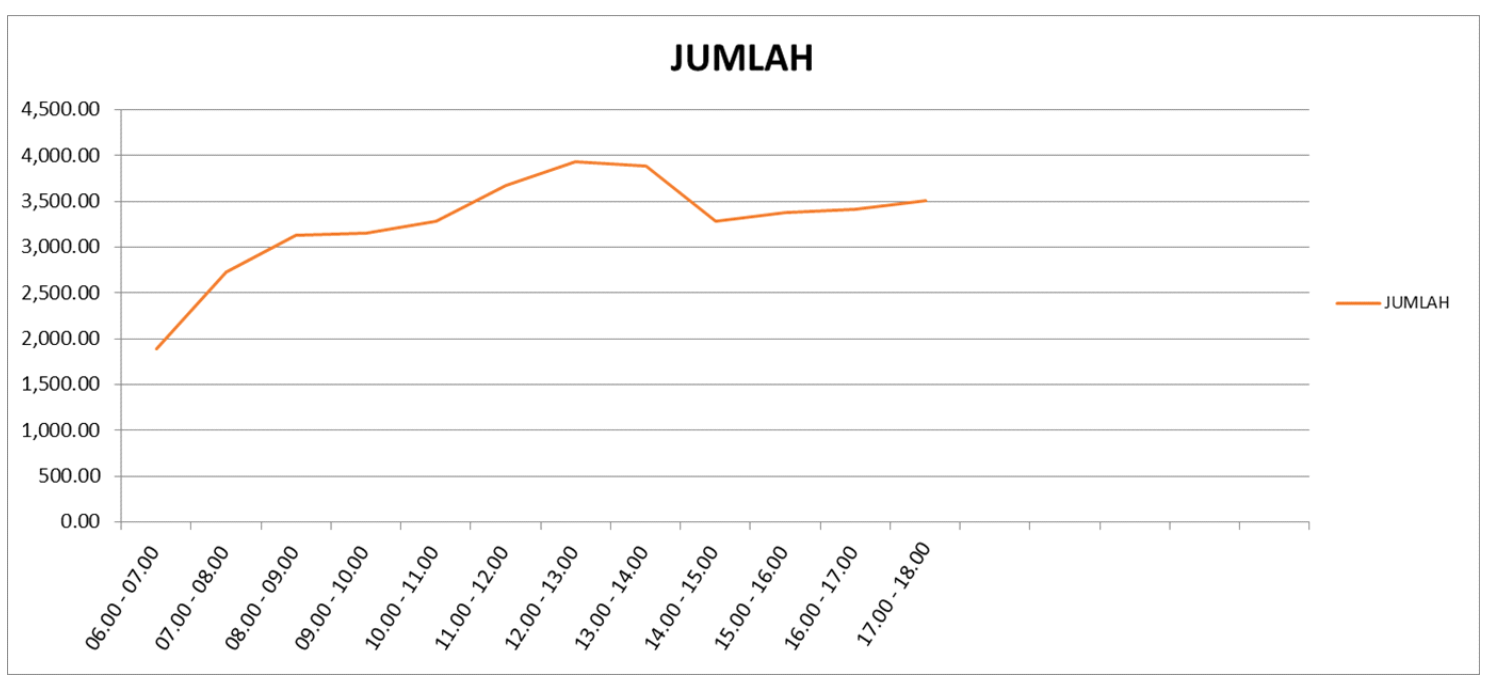

- Derajat Kejenuhan

Derajat kejenuhan (DS) pada persimpangan Yoseph Latumahina yaitu sebesar 0,877 yang dihasilkan dari perbandingan nilai arus lalu lintas total dengan nilai kapasitas.

Grafik 3. Derajat Kejenuhan

- Tundaan simpang

Tundaan lalu lintas pada simpang Jl Penghibur-Jl. Metro Tj. Bunga yaitu sebesar 11,96/smp seperti yang terlihat pada tabel berikut yang diperoleh dari penjumlahan nilai tundaan geometric simpang yaitu sebesar 4,289

Peluang antrian pada Simpang empat J1 Penghibur-Jl. Metro Tj. Bunga yaitu $48 \%$ sampai dengan $63 \%$ yang dihasilkan dari hubungan empiris antara peluang antrian dan derajat kejenuhan pada batas atas dan batas bawah, adapun nilai batas atas yaitu sebesar $48 \%$ dan batas bawah sebesar $63 \%$, Perilaku lalu lintas simpang dapat dilihat pada tabel dibawah ini.

Tabel 3. Perilaku Lalu Lintas Simpang

\begin{tabular}{lccc}
\hline No & Perilaku lalu lintas & & Nilai \\
\hline 1 & Arus lalu lintas & $\mathrm{Q}$ & 3272,19 \\
\hline 2 & Derajat kejenuhan & $\mathrm{DS}$ & 0,877 \\
\hline 3 & Tundaan lalu lintas simpang & $\mathrm{DT}_{1}$ & 11,96 \\
\hline 4 & Tundaan lalu lintas jalan utama & $\mathrm{D}_{\mathrm{ma}}$ & 8.47 \\
\hline 5 & Tundaan lalu lintas jalan minor & $\mathrm{D}_{\mathrm{mi}}$ & 15,700 \\
\hline 6 & Tundaan geometrik simpang & $\mathrm{DG}$ & 4,289 \\
\hline 7 & Tundaan simpang & $\mathrm{D}$ & 16,245 \\
\hline 8 & Peluang antrian $(\%)$ & Qp atas & 48 \\
\cline { 2 - 4 } & & Qp bawah & 63 \\
\hline
\end{tabular}

Grafik 4. Tundaan Simpang 
- Kecepatan Kendaraan

Kecepatan kendaraan dari simpang empat Jl Penghibur-Jl. Metro Tj. Bunga dapat dilihat pada tabel dan grafik berikut

Grafik 5. Grafik rata-rata Kecepatan pada Simpang 4 Jl. Penghibur - Jl. Metro Tj. Bunga

\section{PENUTUP}

\section{Kesimpulan}

- Jika dilihat dari indikator jumlah kenderaan per jam dan derajat kejenuhan (DS) menunjukkan nilai relatif lebih tinggi pada interval waktu siang dan sore dibandingkan pagi

- Derajat kejenuhan (DS) pada waktu pagi, siang dan sore adalah 0,877. Nilai DS tersebut lebih besar dari nilai ambang batas 0,85 (MKJI 1997). Dengan nilai DS tersebut ruas Jalan Raya dalam analisa operasional masih belum memenuhi operasional jalan perkotaan.

\section{Saran}

Disarankan agar menambahkan opsi jalan lain menuju jalan Metro tanjung bunga yang tidak terlalu jauh atau membuat trafick light dijalan simpang empat tersebut

\section{DAFTAR PUSTAKA}

Carlos F.Daganzo, Fundamentals of Transportation and Traffic Operations,PergamonElsevier,Oxford, U.K. 1997.

Daganzo, Carlos F. A Simple Traffic Analysis Procedure. Networks and Spatial Economics, 2001

Kermer, B. S., The Physics of Traffic, Springer, Berlin, New York 2004

May, Adolf. Traffic Flow Fundamentals. Prentice Hall, Engewood Cliffs. NJ,1990

http/www.scribd.com/doc/51981259/Traffic-Volume-survey

Manual Kinerja Jalan Indonesia, 1997

Panduan Survei Perhitungan Waktu Perjalanan Lalu Lintas. Direktorat Jenderal Bina Marga. Direktorat Pembinaan Jalan Kota. N0. 001/T/BNKT/1990

Peraturan Menteri Perhubungan NO. KM 14, 2006. tentang Manajemen dan Rekayasa Lalu Lintas di Jalan. 